\title{
Vietnam's Educational Philosophy Statement for Human Being, for Prosperous Development
}

\begin{abstract}
Dr. Dinh Nguyen An
Vietnam University of Traditional Medicine

Abstract

The author's article focuses on analyzing and clarifying the scientific basis, contributing to affirming that Vietnam has an educational philosophy statement of training talents. The weaknesses of Vietnam's education today originate from lack of inheritance, application, supplementation and development of the existing educational philosophy statement in line with the era of globalization, international integration and knowledge economic development and industrial revolution 4.0. Besides, the state management mechanism and education and training processes, stages and steps are not professional and effective. Therefore, in addition to continuing to research, improve and develop the educational philosophy statement in line with the new situation, Vietnam should pay attention to mechanisms, policies and innovation of operating procedures of the whole political system, first of all, the Ministry of Education and Training to implement Vietnam educational philosophy statement in a more synchronous, comprehensive and effective way.
\end{abstract}

Keywords: Education, educational philosophy statement, Vietnam'seducational philosophy statement, innovation, development, teachers, lecturers.

DOI: $10.7176 /$ RHSS/9-8-11

Publication date: April $30^{\text {th }} 2019$

\section{Rationale}

"Whether Vietnam has aneducational philosophy statement or not" has been studied and discussed by many Vietnamese scientists for recent times. There are many different views and opinions; however, basically, it is agreed that it is not true that we have had no educational philosophy statement since ancient times. In facteach era and each historical period has its own educational philosophy statement. Therefore, many scientists believe that thanks to the educational philosophy statement, Vietnam becomes a civilized, peaceful and independent country; has international cooperation with most of the nations and peoples worldwide and supported and assistedby international friends. In general, Vietnameducational philosophy statement is aimed at training talents - good quality human resources, having enough virtues and capabilities to meet the social development. However, due to the limitations and shortcomings of Vietnamese education today, many people are skeptical or deny Vietnamese education's achievements. Since then, they say that Vietnam does not have an educational philosophy statement or has an outdated educational philosophy statement. Therefore, the purpose of the author is to focus on analyzing, distinguishing the educational philosophy statement and philosophy of education, thereby affirming whether Vietnam has had any educational philosophy statementsince ancient times or not. If any, what is the content of that educational philosophy statement? why cannot it be effective in the new era? Vietnam's educational philosophy statement has a formation and developmentprocess, constantly adding and perfecting to suit each historic period of the country. The current limitations and weaknesses of Vietnamese education are not entirely due to the lack of educational philosophy statement or the outdated and inappropriate educational philosophy statement but due to many factors, constraints and development obstacles, especially the management mechanism and implementation stages are not professional, comprehensive, synchronous and effective.

\section{Educational Philosophy Statement and Philosophy of Education}

Regarding the issue of whether Vietnam has an educational philosophy statement or not, there are many workshops held with many different views and opinions but basically, it is agreed that we do not have any educational philosophy statement because without an appropriate educational philosophy statement, Vietnamese society cannot develop and Vietnam does not have a thousand-year history. Every educational philosophy statement of Vietnam has been aimed at the ultimate goal of training people with the best virtues and capabilities to meet social development. According to Ms. Vu Thi Hang who has summarized many opinions and views on educational philosophy statement in domestic articles and seminars, "Educational philosophy statement is all core views, basic principles and motto of action to orient and direct the organization and operation of the country's education system on the basis of certain specific historical conditions of the society" $2 ; \mathrm{p} .17]$. The philosophy of education is a viewpoint reflecting the issues of education through the way of experiencing thelife to direct the thinking and is the motto of human action on education issues.

We believe that the philosophy of education is a science that studies and applies philosophical methods to solve education problems and are the main and common methodological principles as a basis for scientific research and educational practice improvement. Philosophy of education plays an indispensable role in building an educational philosophy statement. The research object of the philosophy of education is human education in the 
direction of the philosophy of education but not education in general.

Thus, "Educational philosophy statement" and "Philosophy of education" are nearly synonymous in the object of access but different in the method of generalization and practical application. "Philosophy of education" as a philosophy science takes education as the research object and uses the concepts, categories, rules and methods of philosophy to explain and discover the intrinsic relationships of education as well as the relationship of education and social life; thereby indicating the development trend of education in specific historical conditions. Vietnam's "educational philosophy statement" is the fact that education has been experienced by Vietnamese people, communities and society and communicated and passed down by generations. It has become a value expressed through short sentences such as maxims, folk-songs, idioms, proverbs, phrases, etc. in order to teach, impart, help the descendants inherit, absorb and express them in life; bringing a oriented value and certain guidance to people, communities and society to continue to inherit, build and protect the country with the noble reason for living: learn to be human, to live, to contribute to the progress of an ethical, legal, humanitarian, peaceful and prosperous society.

Thus, the educational philosophy statement is the viewpoints and basic principles to orient and direct the organization and operation of the education system of the country based on certain specific historical conditions of the society.

\section{Vietnam has an educational philosophy statement or philosophy of education?}

Each educational philosophy statement is formed from the requirements, socio-economic characteristics, cultural characteristics, the political regime of the nation and the reality of the era. Therefore, the educational philosophy statement is always changed, supplemented and perfected and developed to suit the requirements of practice. Indeed, culture - science development, educational philosophy statement must also be rethought, supplemented and perfected to suit the requirements of social life and the requirements of the era. The educational development history of continents from Europe and America has witnessed the succession of many different educational philosophy statements, from ancient Greece to the Middle Ages to the Renaissance, Age of Enlightenment, etc. since the past. In modern times, there are educational philosophy statements associated with names such as: K.Marx, J. Dewey, Albert Einstein, M. Foucault ... and many otherfamous philosophers - educators with the outstanding careers. Thus, from the tradition to the present, Vietnam has had educational philosophy statements, which have not been built into a massive theoretical systemyet but also enough for the Vietnamese people to exist and develop with thousands of years of culture. Therefore, the difference between Vietnamese traditional educational philosophy statement and Western development educations is not to generalize those educational philosophy statement values into doctrines and views on education as an orthodox doctrine. This difference does not mean that Vietnam is inferior and lags behind Western countries; on the contrary, it enriches knowledge as well as the conception of Vietnam's educational philosophy statement, integrating into the educational philosophy statement of the nations and peoples in the world.

The construction and development of Vietnam's educational philosophy statement is a process, so every development stage of Vietnamese education is associated with a certain educational philosophy statement, specifically:

In the feudal regime, the educational philosophy statement of the Vietnamese influences and is closely associated with Confucian educational philosophy statement. The goal of education is to train military people in the fixed patterns with full elements of "three moral bonds and five constant virtues", knowing "Self Educating, Family Managing, National Managing \& Pacifying the World". The main teaching method is communication and comprehension. The purpose of the study is to become mandarins andapply the moral standards to "assist the king, help the people and the country" and at least, to become teachers who train talents for the country. Beside the Confucian educational philosophy statement, Vietnam still has the folk educational philosophy statement, which is drawn on the thousands of years' traditional values expressed through profound proverbs, idioms, and folk songs such as: "No guide, no realization"; "To have your child well-educated, pay much attention to his/ her teacher", "Visit Paternal side on the first day, Maternal side on the second day and Teachers on the third day" and "No matter how stupid you are, only be patient, you are surely good", "Better learn your friend than your teacher", "Travel broadens the mind", "A man is known by the company he keeps", "one must learn how to eat, how to talk, how to wrap and how to unwrap"(It means that everything must be learned at anytime, anywhere). The ancients' philosophy of self-study handed down to children today is very useful, many things are still intact in their values and need to be inherited and developed the positive aspects.

During French colonial rule, Vietnamese education was influenced by Western education brought by the French in the process of aggression and rule. Western education has gradually replaced Vietnamese feudal education. This education is based on the philosophy statement of the enlightenment ideology created from industrial civilization with ideas about human rights, civil rights, democracy and the rule of law state, etc. Although Vietnamese education developed slowly in a semi-feudal colonial society when the social reality was always contrary to noble philosophies, Vietnamese education still had "evocative" philosophy statements. In fact, 
many true French professors brought the light of progressive enlightenment philosophy into the backward education of Vietnam at the time, which made radical, conservative scholars with outdated views gradually awake, overcome the stigma of discrimination and initially follow the advanced education of the West. The French colonial educational philosophy statement has influenced and demonstrated the values of national consciousness, patriotism, spirit of studiousness, family values and the philosophy of human love through thinkers such as PhanBoi Chau, Phan Chu Trinh, etc.

Ho Chi Minh's educational philosophy statement - the great leader of the Vietnamese people, the founder of the Democratic Republic of Vietnam (1945, now the Socialist Republic of Vietnam) comes from the philosophical thought on humanism with the system of philosophy of liberation, development and creation on the basis of inheriting and applying Marxist philosophy and cultural and educational values in the world. The whole Ho Chi Minh's ideology and his career of revolutionary activities also come from the people and the goal of liberating people (class liberation, national liberation and humanity liberation). Ho Chi Minh's educational philosophy statement: All for the sake of people, for people and thanks to people. "Learning to be a human being, learning to serve the Fatherland and serve the people", learning to become "the people's public servants". Those thoughts and educational philosophy statements still remain intact in their values until now, showing Ho Chi Minh's progress and vision beyond his age:

Regarding the position and role of education, Ho Chi Minh soon determined: "If your plan is for ten years, plant trees. If your plan is for one hundred years, educate children" [9; p. 528]. The career of "educating children" plays a decisive role in survival and development of each nation and people. Therefore, a special priority must be given to education and education must be considered as a top national policy, especially in the specific context of Vietnam at that time.

Regarding the educational purposes: education for human being. Ho Chi Minh conceived: "Learning to work, to be a human being, to be an officer, to serve mass, class and people, the Fatherland and humanity" [6; p. 208]. Education helps people to improve their personalities and create their own values: "The gentleness or cruelty is not innate but much due to the educational method" [5; p.413].

Regarding the educational method: "Learn at school, learn from books, learn from each other and learn from people" [7; p. 361]. "Life-long learning" has been repeatedly reminded by Ho Chi Minh ("Learning is a continuation of life" [8; p.377].

Regarding the educational contents: Teaching about cultures, politics, military, morality, ideology, lifestyle, creative, independent and exploratory methods "to apply them creatively to the real situation of Vietnam".

Regarding the educational methods: mainly self-study, "discussion and direction" [6; p.312]. Educational motto: the argument must be associated with practice, learning must go hand in hand with productive labor, education must be practical.

Ho Chi Minh's educational philosophy is expressed through his speeches and direct teachings which are simple expressions but show a high level of comprehension, profound meaning drawn from the experience of educational practice in the following contents: Against the idiocy policy; an ignorant nation is a weak nation; If your plan is for one hundred years, educate children; Building an education of an independent country; training useful citizens; developing children's existing capacity; Employing talents; education to be a human being; learning goes hand in hand with practice, theory is tied to practice.

Educational philosophy statement after the August Revolution in 1945: Under the educational philosophy statement of Ho Chi Minh, the education after the August revolution mainly expressed the Party and the State's educational development policy through "Popular educational philosophy statement", "New democratic educational philosophy statement" (ethnicity, science, mass), "comprehensive educational philosophy statement" (comprehensive human development).

\section{Educational philosophy statement of the renovation period (after 1986)}

Over the past years, Vietnam has received and learned to follow Ho Chi Minh's thoughts and philosophy statements throughout the process of revolutionary activities; however, today they needs to be thoroughly understood and applied in a way that is consistent with the new conditions. Under Ho Chi Minh's philosophy of education, the Communist Party and the State of Vietnam continue to supplement and develop in line with the requirements of historical periods, specifically in documents, guidelines, education and training development policies and strategies and Vietnamese cultural and human development strategies, etc.

Educational development policyin the innovation period: The education and training development is the top national policy, investment in education and training is investment in sustainable development. "Expanding democracy, maximizing human factors; regarding people as the subject, the main resource and the goal of development" [1; p.100]. The mission of education and training is improving people's intellectual standards, developing human resources, fostering talents and building a Vietnamese culture. The education and training development motto is improving the quality based on the requirements of standardization, modernization, socialization and democratization; building a learning society, creating opportunities and conditions for all citizens to be lifelong learners. 
The State of Vietnam has built and affirmed the educational philosophy statement of the renovation period: Continuing to implement the fundamental and comprehensive education and training innovation policy and the orientation: Education is the top national policy. Education and training development is to improve people's intellectual standards, train human resources and foster talents. Vietnam has strongly shifted its educational process from primarily providing knowledge to comprehensively developing learners' capabilities and virtues; education and training development must be associated with the needs of economic development, national construction and defense, scientific and technological advances; striving to make drastic and fundamental changes in education and training quality and efficiency in the coming years and make Vietnam's education become an advanced education in the region by 2030 .

4. The existing issues of Vietnam's educational philosophy statement in the context of globalization and international integration acceleration

Currently, Vietnam has an educational philosophy statement. "Vietnam's educational philosophy statement is primarily a philosophy of building a strong, democratic, fair and civilized country. It is to build a Vietnamese people who are comprehensive, virtuous, beautiful, nationalistic; have patriotism and international responsibility"[11]. So, Vietnam has an educational philosophy statement but still lags behind and is inferior to other countries in the region and the world? Is Vietnam's educational philosophy statement obsolete, no longer suitable for the development of contemporary Vietnamese society? The current situation of Vietnamese education shows that:

- The main purpose of learning is to pass the exam but not to know, to do, to assert yourself; learning is based on the exam-oriented contents.

- The education contents are strictly controlled in the form of textbooks and teachers' books. Teachers work based on the syllabus, students learn based on the syllabus and books. Education imposes the available knowledge. There is no creativity and newness according to the progress of social practice.

- The main teaching method in Vietnam is one-way communication and traditional reading-writing method. The main learning method is learn by heart. Discussion is to develop critical thinking, independent thinking and creativity has not been promoted and not encouraged. In particular, for social sciences, both teachers and students only applied a formal interpretation.

These characteristics show that the current Vietnamese education system does not encourage learners to actively form the creative thinking and is still under imposition. At the same time, the current education does not encourage learners to explore by themselves to build new knowledge for themselves but memorize and admit knowledge as the truth already existed. Therefore, people created from this system are not equipped with enough basic and in-depth knowledge, not updated new skills to compete and adapt to the international environment because the way of learning by heart, memorizing, studying the selected contentsonly, learning to take the exam only. Good academic performance in this way of learning is understood to be good learning, good exam-taking but not really good-working and good-living. Thus, the goal and guideline of learning coupled with practice, the theory associated with practice has not been effectively implemented.

However, such educational philosophy statement has been effectively promoted and consistent with the history in the period when Vietnam experienced war. Currently, the situation has changed, Vietnam is entering a period of global integration, the need for creativity and personal autonomy and critical thinking becomes an urgent requirement, the educational philosophy statement is no longer suitable, causing obstacles for social progress, especially not in line with the era of globalization, international integration, development of knowledge economy and the industrial revolution 4.0. Vietnam is stepping up the development of a market economy, completing the national industrialization and modernization, striving to become a modern industrial country on the occasion of the $100^{\text {th }}$ anniversary of the country's establishment.

First of all, the result of implementing this educational philosophy statement is to create a fame-seeking society. Fame-seeking means learning mainly to get a degree, a certificate, etc. to meet the requirements of qualifications for each job position. However, it is not true that all learners seek fame but the number of fameseeking learners increases day by day. Therefore, if Vietnam does not quickly change the educational philosophystatement and the currenteducation and examination management and evaluation mechanisms and formal admissions, the fame-seeking problem is no longer a phenomenon but become the nature and the common in society.

Although Vietnam abandoned the bureaucratic and State-subsidized mechanism, the field of education also carries its imprint. The educational vision is short-term, formal and only for coping with criteria. Gifted schools and selective classes are not really ideal places to train talents. Therefore, Vietnam has many students who have won international awards, bringing pride to the nation but very few of them later became great scientists of the world.

Secondly, Vietnam's educational philosophy statement is now the source of achievement disease, contributing to developing deceitfulness. In fact, the high school graduation rate in Vietnam is nearly $100 \%$ at high scores but 
$90 \%$ students fails the university entrance exam. There are even stories of collusion of supervisors, lesson reminders, giving documents to students to use in the exams, some teachers' embezzlement and briberyto falsify the exam results in the high school graduation exams, etc.

In the period of developing the market economy and promoting international integration today, if Vietnam wants to develop education on a par with other countries in the region and the world, it must continue to study, change and perfect its educational philosophy statement. In particular, Vietnam has to change the mindset of education, the educationalphilosophy statement from stability orientation to capacity and virtue development orientation, needs not only "obedient children and good students" but also "brave, dare- to- think, dare-to-do, dareto-take- responsibility and creative people". Vietnam needs to build an educational philosophy statement towards training free people, so that learners may have independent thinking, creative thinking, critical thinking instead of training people as tools and purposes of the current system. To achieve this goal, Vietnamese society must be truly democratic and build a rule of law state and people must break away with village community and develop a personal spirit and a sense of community. Vietnam must respect honesty rather than cleverness; a sense of responsibility rather than reliance; the spirit of cooperation for common work rather thanappearances and follow the interests of the group; science and creativity rather thanarbitrariness.

These values must become the target of education reformation. It is necessary to identify the targets and issues such as the structure of educational levels, programs and textbooks appropriately based on the educational philosophy statement. Besides, the important requirement is that Vietnam must fundamentally change the teaching and evaluation methods; the way of thinking, the way of doing of teachers and education managers, which is the determining factor of the quality of education today.

Vietnamese education is no one's own job. Vietnamese education is a problem of the whole society. It needs to be socialized and concerned by the society who are responsible for developing the education of the country. Therefore, in order to develop Vietnamese education, besides rethinking about the educational philosophy statement, it is necessary to have a synchronous change from the implementation mechanism to the whole social system's awareness of modern Vietnamese education.

\section{Conclusion}

Education as well as Vietnamese society needs to be reformed and developed but the characteristics of education require Vietnamese education to be standardized, stabilized, developed and modern on all aspects: Educational thought, educational plan, educational action. Teachers and students- the main relation which makes the school history and Vietnamese education history - are creative, proactive and responsible subjects. The most pressing issue today is that Vietnam must change its thinking, design, shape and deploy a new education and training philosophy synchronously; build Vietnam's educational philosophy statement of humanism- Education for sustainable human development.

\section{References}

1. The Communist Party of Vietnam (2011), the document of the $11^{\text {th }}$ National Congress, the National Political Publishing House, Hanoi.

2. Dr. Vu Thi Hang (2017), Intellectuals at universities in the process of developing Vietnam's educational philosophy statement, Vietnam Education Publishing House, Hanoi.

3. Ho Chi Minh (2011), All volumes, Vol. 5, 6, 6,9, the National Political Publishing House, Hanoi.

4. Assoc. Prof. Dr. Nguyen Xuan Trung (2015), "Vietnam's educational philosophy statement: From traditional educational philosophy statement to Ho Chi Minh's educational philosophy statement", Journal of Political Theory, No. 1, 2016.

5. Ho Chi Minh (2011), All volumes, Vol. 3, the National Political Publishing House, Hanoi, p. 413.

6. Ho Chi Minh (2011), All volumes, Vol. 5, the National Political Publishing House, Hanoi, p. 312.

7. Ho Chi Minh (2011), All volumes, Vol. 6, the National Political Publishing House, Hanoi, p.361.

8. Ho Chi Minh (2011), All volumes, Vol. 9, the National Political Publishing House, Hanoi, p. 377.

9. Ho Chi Minh (2011), All volumes, Vol. 11, the National Political Publishing House, Hanoi, p. 528.

10. Giap Van Duong (2014), "Naming the educational philosophy statement",http://www.thesaigontimes.vn/114544/Goi-ten-triet-ly-giao-duc.html.

11. Minh Thuy (2016), "Vietnam has an educational philosophy statement but no classic quotations", $\mathrm{http} / / /$ vneconomy.vn/thoi-su/viet-nam-co-triet-ly-giao-duc-chi-khong-co-trich-dan-kinh-dien201611160444468.htm. 